\title{
Phase formations in tungsten carbide films deposited by reactive magnetron sputtering
}

\author{
L. Haus ${ }^{1,2}$, M. Thümmler ${ }^{1}$, J. Wöckel${ }^{2}$, C. Wüstefeld ${ }^{1}$, M. Müller², D. Rafaja ${ }^{1}$ \\ ${ }^{I}$ Institute of Material Science, TU Bergakademie Freiberg, D-09599 Freiberg \\ ${ }_{2}^{2}$ Plasma Technology, Robert Bosch Manufacturing Solutions GmbH, D-70442 Stuttgart
}

Lea.Haus@de.bosch.com

The tungsten carbide films were deposited by reactive magnetron sputtering in an industrial-scale coating chamber at different bias voltages and gas (argon/acetylene) flows. As substrate materials, silicon wafers and 100Cr6 steel sheets were used. The films were characterized using electron probe microanalysis with wavelength-dispersive X-ray spectroscopy (EPMA/WDX) and in situ hightemperature X-ray diffraction (HTXRD). EPMA revealed the chemical composition of the films; HTXRD gave overview over the thermally activated phase transformations and stabilization of metastable phase through the microstructure defects. The as-deposited films contain metastable phases $\mathrm{WC}_{1-\mathrm{x}}$ and $\mathrm{W}_{2} \mathrm{C}$ with distorted crystal structures. With increasing temperature and/or longer annealing time, the crystal structure of the high-temperature $\mathrm{W}_{2} \mathrm{C}$ phase recovered, although the annealing temperature was below the temperature, which is required to make $\mathrm{W}_{2} \mathrm{C}$ thermodynamically stable. The density of the microstructure defects in $\mathrm{W}_{2} \mathrm{C}$ was reduced, but some defects persisted. The structure relationships between individual phases will be discussed. Further heat treatment resulted in a decomposition of $\mathrm{W}_{2} \mathrm{C}$, which was accompanied by the formation of metallic tungsten. The EPMA results confirmed that this decomposition is accelerated by the reaction of carbon with oxygen impurities in the annealing atmosphere. When the $100 \mathrm{Cr} 6$ steel is used as substrate material, $\mathrm{W}_{3} \mathrm{Fe}_{3} \mathrm{C}$ forms at the interface between the substrate and the coating. The presence of this carbide influences the decomposition of $\mathrm{W}_{2} \mathrm{C}$.

Keywords: tungsten carbide; thin film; sputtering; phase transformations; $x$-ray diffraction 